\title{
Europe proposes orphan drug legislation
}

The European Commission (EC; Brussels, Belgium) presented a proposal at the end of June to the European Parliament to introduce orphan drug legislation in Europe. The proposal, which is not expected to be implemented until 2000 , would result in major involvement from the European Medicines Evaluation Agency (EMEA; London)-the body responsible for giving European Union (EU)-wide drug approvals in Europe. Proposed incentives would encourage small companies in particular to develop orphan drugs-those aimed at rare diseases. Although industry and patient bodies, which pressured for the legislation, have welcomed the incentives, there are concerns that the vague economic criteria-which may curtail the period of market exclusivity for an orphan drug-may discourage larger companies from developing this type of drug.

The new proposal, "The European Parliament and Council Regulation on Orphan Medicinal Products," calls for the EMEA to establish a Committee for Orphan Medicinal Products to decide which orphan drug applications to approve, and to oversee the orphan drug approval process. The idea is to provide incentives to companies in the 15 EU countries in order to encourage the development of orphan drugs. The United States has had orphan drug legislation since 1983 , when its Orphan Drug Act was established. According to PhRMA (Pharmaceutical Research Manufacturers of America; Washington, DC), the US act-which served as a prototype for a program adopted in Japan in 1993 - also forms the basis of the EC initiative.

Under the proposal, a company selling an orphan drug would normally have market exclusivity of 10 years. This means that only that company can sell a drug to a specified market, in effect giving that company a monopoly on that market for up to 10 years. This compares with seven years in the United States.

There would also be financial incentives. A company usually pays around Ecu140,000 (US\$154,360) for a new drug application. Valuation and maintenance fees during and after drug approval can amount to an additional Ecu100,000 (US $\$ 110,450$ ). However, for EMEA orphan drugs these fees would be waived. Since the 1997 US Food and Drug Administration (Rockville, MD) legislation, the waiver of fees for orphan compounds has been formalized.
In addition, the EMEA will provide help with clinical trials. "[Companies] will be able to consult us on how to put together clinical trials to provide suitable data for approval," says Antoine Cuvillier, a legal advisor at the EMEA. According to Cuvillier this is impor-

\section{The niche status of the \\ orphan drug market will} appeal to smaller biotechnology companies that may have less experience and resources to conduct trials.

tant for several reasons. He believes the niche status of the orphan drug market will appeal (although not exclusively) to smaller biotechnology companies that may have less experience and resources to conduct trials. In addition, there will be far fewer data to present for an orphan drug owing to the rarity of patients. "If a product has insufficient data there [is provision in the legislation that could] allow the drug through," says Cuvillier. However, in this scenario, the EMEA would continue to monitor the drug

The impact of Orphan Drug Legislation. In the US, 10 orphan drug applications were approved in the decade before the Orphan Drug Act, compared to 99 in the decade following the act.

postapproval to ensure that efficacy is sufficient to treat the disease.

The proposal defines an orphan drug using epidemiological criteria-the prevalence of the disease-which is set at five patients per 10,000 , a figure that compares with 7.5 per 10,000 in the United States and four per $10,000 \mathrm{in}$ Japan. However, there is an exclusivity reduction clause whereby "[if] an orphan medicinal product is proving more profitable than had been foreseen, any Member State [of the EU] may request that the exclusive marketing rights be withdrawn at the end of the sixth year." There is some concern that this is vague, difficult to quantify, and could have severe consequences.

Economic concerns about orphan drugs were raised in the United States by Amgen's (Thousand Oaks, CA) erythropoietin and Genentech's (South San Francisco, CA) human growth hormone, both of which turned out to have sales of more than $\$ 250$ million a year, far more than anticipated for an orphan drug. (Nature Biotechnology 14:420, 1996).

Jurgen Reden, research and development advisor to the European Federation of Pharmaceutical Industries' Association, (EFPIA; Brussels), which lobbies on behalf of the pharmaceutical industry, sees serious problems with a strategy based on economic criteria. "Who is going to define what profits are unreasonable?" he asks, adding that the ambiguous definition could deter otherwise interested companies.

In addition, Erich Tambuyzer, a board member of EuropaBio (Brussels) - the European biotechnology trade association, which has pioneered and promoted the introduction of orphan drug legislation in Europe--points out that, in order to have profits assessed, a company would have to open its books to authorities, possibly exposing sensitive information. "It's too intrusive for what would only ever be a small product, and as a result [large companies] will not bother with orphan drugs."

Inevitably this leaves the path clear for smaller companies to take the lead in developing orphan drugs-something that both Reden and Tambuyzer expect to happen based on their experience of orphan drug companies in the United States. However, Tambuyzer thinks that deterring larger firms could diminish the potential benefits of having orphan drug regulations.

Reden suggests changing the market-exclusivity criteria to specify the number of patients treated. "If the drug was expected to go to 200,000 patients but ended up going to a million, then there are grounds to remove orphan drug status." The advantage of this mechanism is that, like disease prevalence, it is quantifiable.

Adam Michael 